\title{
Bacteroides sartorii is an earlier heterotypic synonym of Bacteroides chinchillae and has priority
}

\author{
Mitsuo Sakamoto and Moriya Ohkuma \\ Microbe Division/Japan Collection of Microorganisms, RIKEN BioResource Center, Wako, \\ Saitama 351-0198, Japan
}

Correspondence

Mitsuo Sakamoto

sakamoto@jcm.riken.jp

\begin{abstract}
Strains of the recently proposed species Bacteroides chinchillae share more than $99.4 \% 16 \mathrm{~S}$ rRNA gene sequence similarity with the type strain of Bacteroides sartorii although these two species do not appear to be similar from their published descriptions. The aim of this study was to perform phenotypic and genetic analyses of both species to clarify their taxonomic position. $B$. chinchillae JCM $16497^{\top}$ exhibited high $h s p 60$ gene sequence similarity with $B$. sartorii JCM $17136^{\top}(100 \%)$ as well as $B$. chinchillae JCM $16498(100 \%)$. The $h s p 60$ gene sequence analysis and levels of DNA-DNA relatedness observed demonstrated $B$. sartorii JCM $17136^{\top}, B$. chinchillae JCM $16497^{\top}$, and $B$. chinchillae JCM 16498 are members of a single species. Based on these data, we propose Bacteroides chinchillae as a later heterotypic synonym of Bacteroides sartorii. An emended description of $B$. sartorii is provided.
\end{abstract}

Clavel et al. (2010) described Bacteroides sartorii, which was isolated from the caecum of a TNF ${ }^{\text {deltaARE }}$ mouse, as a novel species within the genus Bacteroides. B. sartorii was closely related to Bacteroides massiliensis, Bacteroides dorei and Bacteroides vulgatus ( $\leqslant 94 \% 16 \mathrm{~S}$ rRNA gene sequence similarity between strains). Kitahara et al. (2011) isolated a novel Bacteroides species, Bacteroides chinchillae, from chinchilla (Chinchilla lanigera) faeces. This species was related to the above-mentioned three species as well as to B. sartorii. From their published descriptions, B. sartorii and $B$. chinchillae appear to be different species. However, the two type strains exhibit 99.6\% 16S rRNA gene sequence similarity; they differ by only 5 bases in their almost full-length sequences (1490 nt). The present study was designed to determine the taxonomic status of $B$. sartorii and $B$. chinchillae by using a polyphasic taxonomic approach.

Bacteroides sartorii JCM $17136^{\mathrm{T}}$, and Bacteroides chinchillae JCM $16497^{\mathrm{T}}$ and JCM 16498 were used in this study. The strains were maintained on Eggerth Gagnon (EG) agar (Merck) supplemented with $5 \%(\mathrm{v} / \mathrm{v})$ horse blood for 2 days at $37{ }^{\circ} \mathrm{C}$ in an atmosphere containing $100 \% \mathrm{CO}_{2}$. Bacteroides bile aesculin agar (Shah, 1992) was used to check whether the growth of the strains was inhibited on this medium.

Physiological reactions were determined with an API 20A anaerobe test kit in duplicate as recommended by the

The GenBank/EMBL/DDBJ accession numbers for the 16S rRNA gene sequences of $B$. sartorii JCM $17136^{\top}$, and B. chinchillae JCM $16497^{\top}$ and JCM 16498 are AB572597, AB547636 and AB547637, respectively, and those for their partial $h s p 60$ gene sequences are AB641323, AB547549 and AB547550, respectively. manufacturer (bioMérieux). Fatty acid methyl esters were obtained from about $40 \mathrm{mg}$ wet cells by saponification, methylation and extraction using minor modifications (Kuykendall et al., 1988) of the method of Miller (1982). Cellular fatty acid profiles were determined by the Sherlock Microbial Identification System (MIDI) version 2.99B with database BHIBLA (version 3.80). Isoprenoid quinones were extracted (Komagata \& Suzuki, 1987) and analysed (Sakamoto et al., 2002) as described previously. Biochemical reactions were determined with the Rapid ID 32A anaerobe identification kit in duplicate as recommended by the manufacturer (bioMérieux). Chromosomal DNA was isolated by previously described methods (Marmur, 1961; Saito \& Miura, 1963), with some modifications. The DNA $\mathrm{G}+\mathrm{C}$ content was determined by the HPLC method of Tamaoka \& Komagata (1984). The elution solvent was a mixture of $0.02 \mathrm{M} \mathrm{NH}_{4} \mathrm{H}_{2} \mathrm{PO}_{4}$ and acetonitrile $(20: 1, \mathrm{v} / \mathrm{v})$. The DNA-DNA hybridization experiments were carried out in microplate wells, as described by Ezaki et al. (1989). Hybridization was performed at $42.5{ }^{\circ} \mathrm{C}$ for $16 \mathrm{~h}$. The $16 \mathrm{~S}$ rRNA gene was analysed as described previously (Sakamoto et al., 2002). The partial hsp60 gene was analysed as described previously (Sakamoto \& Ohkuma, 2010; Sakamoto et al., 2010). Related sequences were aligned with the program CLUSTAL_X 2.0 (Larkin et al., 2007) and corrected by manual inspection. Nucleotide substitution rates ( $K_{\text {nuc }}$ values) were calculated (Kimura, 1980) after gaps and unknown bases were eliminated. The phylogenetic tree was reconstructed by the neighbour-joining method (Saitou \& Nei, 1987). Bootstrap resampling analysis (Felsenstein, 1985) was performed to estimate the confidence of tree topologies.

B. sartorii JCM $17136^{\mathrm{T}}$, and B. chinchillae JCM $16497^{\mathrm{T}}$ and JCM 16498 were obligately anaerobic, non-spore-forming, 
Table 1. Characteristics of Bacteroides sartorii and Bacteroides chinchillae

Strains: 1, B. sartorii JCM $17136^{\mathrm{T}} ; 2$, B. chinchillae JCM $16497^{\mathrm{T}} ; 3$, B. chinchillae JCM 16498. All strains produced acid from L-arabinose, cellobiose, glucose, lactose, maltose, D-mannose, raffinose, L-rhamnose and D-xylose. All strains failed to produce acid from glycerol, Dmannitol, melezitose, salicin, D-sorbitol and trehalose. All strains were positive for aesculin hydrolysis. All strains were negative for indole production, gelatin digestion, and urease and catalase activities. All strains were positive in Rapid ID 32A tests for $\beta$ - $N$-acetylglucosaminidase, alkaline phosphatase, $\alpha$-arabinosidase, $\alpha$-fucosidase, $\alpha$-galactosidase, $\beta$-galactosidase, $\alpha$-glucosidase, $\beta$-glucosidase, mannose and raffinose fermentation, alanine arylamidase, glutamyl glutamic acid arylamidase, glycine arylamidase and leucyl glycine arylamidase. All strains were negative in Rapid ID 32A tests for indole production, nitrate reduction, urease, arginine dihydrolase, $\beta$-galactosidase-6phosphate, $\beta$-glucuronidase, glutamic acid decarboxylase, histidine arylamidase, phenylalanine arylamidase, proline arylamidase, pyroglutamic acid arylamidase, serine arylamidase and tyrosine arylamidase.

\begin{tabular}{|lccc|}
\hline Characteristic & $\mathbf{1}$ & $\mathbf{2}$ & $\mathbf{3}$ \\
\hline Acid production from sucrose & - & + & + \\
Rapid ID 32A tests & & & \\
$\quad$ Arginine arylamidase & + & - & - \\
Leucine arylamidase & + & - & - \\
\hline
\end{tabular}

non-motile, Gram-negative short rods or rods. Cells on EG agar were $1.0-1.5 \mu \mathrm{m}$ wide and variable in length, mostly $2.0-15.0 \mu \mathrm{m}$. Colonies on EG agar plates after $48 \mathrm{~h}$ of incubation at $37{ }^{\circ} \mathrm{C}$ under anaerobic conditions were $1-$ $2 \mathrm{~mm}$ in diameter, circular, entire, slightly convex, smooth, white-greyish and translucent. B. sartorii and B. chinchillae were able to grow on Bacteroides bile aesculin agar and aesculin hydrolysis was positive. The phenotypic and biochemical characteristics of the two strains of $B$. chinchillae were almost the same as that of the type strain of B. sartorii; the only differential characteristics were sucrose fermentation and arginine arylamidase and leucine arylamidase activities (Table 1).

The cellular fatty acid compositions of the two strains of $B$. chinchillae were similar to that of the type strain of $B$. sartorii (Table 2). The major fatty acids were anteiso- $\mathrm{C}_{15: 0}, \mathrm{C}_{18: 1} \omega 9 c$ and iso- $\mathrm{C}_{17: 0} 3-\mathrm{OH}$ in both species. Amounts of anteiso$\mathrm{C}_{15: 0}$ were slightly lower in B. chinchillae than in B. sartorii. The major menaquinone of $B$. sartorii JCM $17136^{\mathrm{T}}$, and $B$. chinchillae JCM $16497^{\mathrm{T}}$ and JCM 16498 was MK-10 (95.5, 94.8 and $95.5 \%$, respectively). The minor menaquinone of the three strains was MK-9 (4.5, 5.2 and $4.5 \%$, respectively).

Approximately 1500 bases of the 16S rRNA gene sequence were determined for each strain. For the phylogenetic analysis, $1465 \mathrm{bp}$ sequences of each species were used. $B$. sartorii JCM $17136^{\mathrm{T}}$, and B. chinchillae JCM $16497^{\mathrm{T}}$ and JCM 16498 formed a single cluster and a distinct line of descent (Fig. 1). These strains exhibited more than $99.4 \%$ 16S rRNA gene sequence similarity with each other and
Table 2. Cellular fatty acid compositions of Bacteroides sartorii and Bacteroides chinchillae

Strains: 1 , B. sartorii JCM $17136^{\mathrm{T}} ; 2$, B. chinchillae JCM $16497^{\mathrm{T}} ; 3$, B. chinchillae JCM 16498. tr, Trace amount $(<0.5 \%)$; - , not detected. Values are percentages of total fatty acids.

\begin{tabular}{|c|c|c|c|}
\hline Fatty acid & 1 & 2 & 3 \\
\hline \multicolumn{4}{|c|}{ Saturated straight-chain } \\
\hline $\mathrm{C}_{13: 0}$ & - & - & $\operatorname{tr}$ \\
\hline $\mathrm{C}_{14: 0}$ & 1.7 & 1.2 & 3.3 \\
\hline $\mathrm{C}_{15: 0}$ & 1.3 & 0.6 & 2.3 \\
\hline $\mathrm{C}_{16: 0}$ & 4.1 & 3.9 & 5.3 \\
\hline $\mathrm{C}_{18: 0}$ & $\operatorname{tr}$ & 0.9 & 0.6 \\
\hline \multicolumn{4}{|c|}{ Unsaturated straight-chain } \\
\hline $\mathrm{C}_{16: 1} \omega 7 c$ & - & $\operatorname{tr}$ & - \\
\hline $\mathrm{C}_{18: 1} \omega 9 c$ & 10.1 & 13.2 & 15.5 \\
\hline$C_{18: 2} \omega 6,9 c$ & 0.9 & 1.3 & 1.4 \\
\hline \multicolumn{4}{|l|}{ Hydroxy acids } \\
\hline $\mathrm{C}_{14: 0} 3-\mathrm{OH}$ & - & $\operatorname{tr}$ & $\operatorname{tr}$ \\
\hline $\mathrm{C}_{15: 0} 3-\mathrm{OH}$ & $\operatorname{tr}$ & $\operatorname{tr}$ & 0.9 \\
\hline $\mathrm{C}_{16: 0} 3-\mathrm{OH}$ & 4.7 & 9.0 & 11.1 \\
\hline $\mathrm{C}_{17: 0} 3-\mathrm{OH}$ & - & - & $\operatorname{tr}$ \\
\hline iso- $\mathrm{C}_{15: 0} 3-\mathrm{OH}$ & $\operatorname{tr}$ & $\operatorname{tr}$ & - \\
\hline iso- $\mathrm{C}_{16: 0} 3-\mathrm{OH}$ & 0.9 & 1.3 & 1.3 \\
\hline iso- $\mathrm{C}_{17: 0} 3-\mathrm{OH}$ & 14.1 & 15.9 & 10.5 \\
\hline anteiso- $\mathrm{C}_{17: 0} 3-\mathrm{OH}$ & 4.1 & 8.5 & 5.1 \\
\hline \multicolumn{4}{|c|}{ Saturated branched-chain } \\
\hline iso- $\mathrm{C}_{13: 0}$ & 0.5 & $\operatorname{tr}$ & $\operatorname{tr}$ \\
\hline anteiso- $\mathrm{C}_{13: 0}$ & 0.7 & $\operatorname{tr}$ & $\operatorname{tr}$ \\
\hline iso- $\mathrm{C}_{14: 0}$ & 0.8 & $\operatorname{tr}$ & 0.9 \\
\hline iso- $\mathrm{C}_{15: 0}$ & 6.7 & 2.9 & 3.5 \\
\hline anteiso- $\mathrm{C}_{15: 0}$ & 43.7 & 34.7 & 31.1 \\
\hline iso- $\mathrm{C}_{16: 0}$ & $\operatorname{tr}$ & - & - \\
\hline anteiso- $\mathrm{C}_{17: 0}$ & $\operatorname{tr}$ & $\operatorname{tr}$ & $\operatorname{tr}$ \\
\hline \multicolumn{4}{|l|}{ Summed features ${ }^{\star}$} \\
\hline 1 & 0.7 & 1.0 & 2.1 \\
\hline 3 & 2.8 & 2.6 & 2.4 \\
\hline 10 & 0.6 & 1.4 & 1.2 \\
\hline
\end{tabular}

* Summed features represent groups of two or three fatty acids that could not be separated using the MIDI system. Summed feature 1 contains $\mathrm{C}_{13: 1} \omega 1 \mathrm{c}$ and/or $\mathrm{C}_{14: 0}$ ALDE. Summed feature 3 contains one or more of an unknown fatty acid of ECL 13.570 and/or iso- $C_{15: 0}$ ALDE. Summed feature 10 contains one or more of an unknown fatty acid of ECL 17.834 and/or $\mathrm{C}_{18: 1} \omega 11 c / 9 t / 6 t$ fatty acid methyl ester.

were most closely related to B. massiliensis JCM $13223^{\mathrm{T}}$ as described previously (Clavel et al., 2010; Kitahara et al., 2011). In addition, $h s p 60$ gene sequence analysis suggested that the three strains were members of the same species (100\% hsp60 gene sequence similarity) (Fig. 1). The $h s p 60$ gene has been found to be an alternative phylogenetic marker for the classification of species of the genus Bacteroides (Sakamoto et al., 2010).

The DNA G + C contents of B. chinchillae JCM $16497^{\mathrm{T}}$ and JCM 16498 were 44.1 and $44.4 \mathrm{~mol} \%$, respectively. These 
(a)

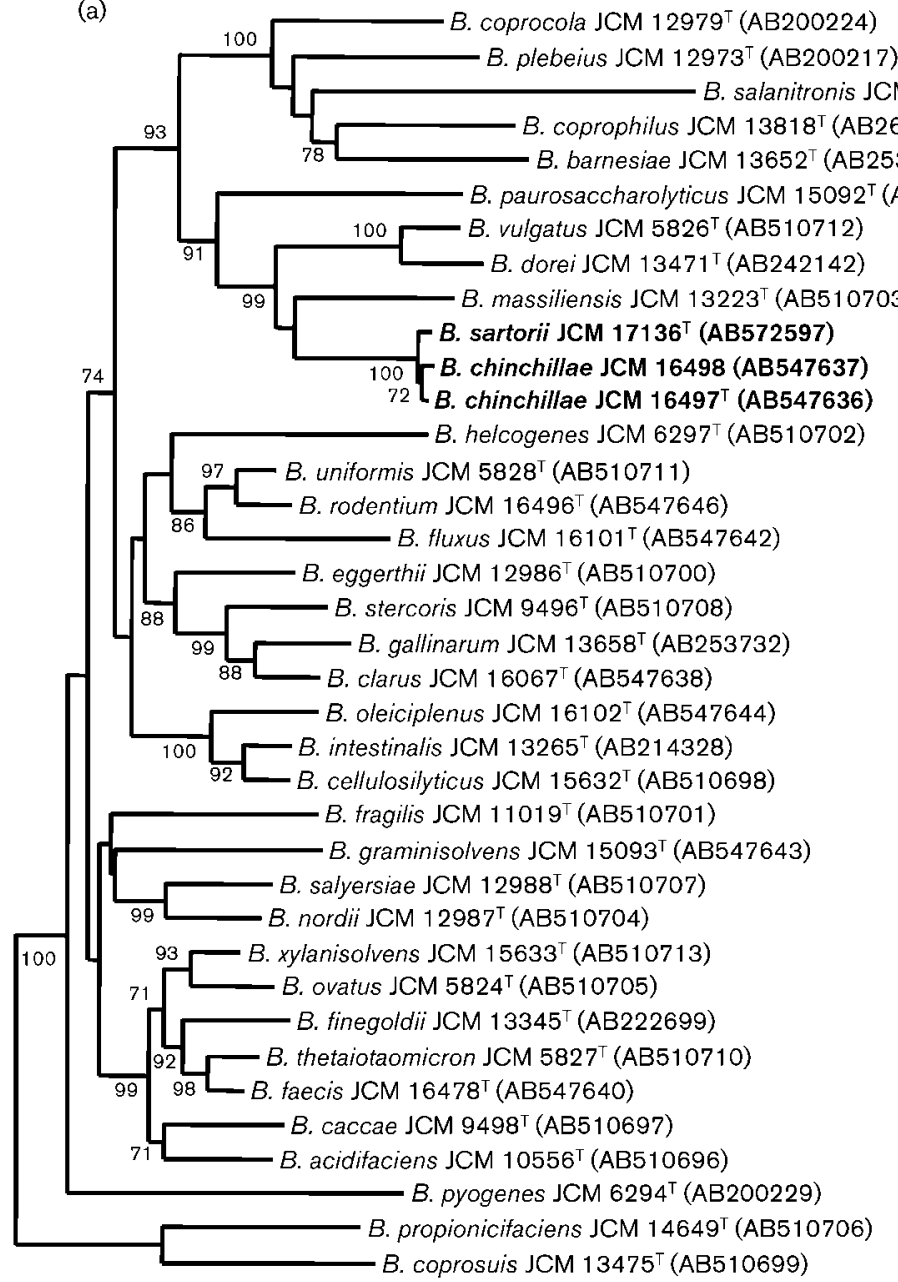

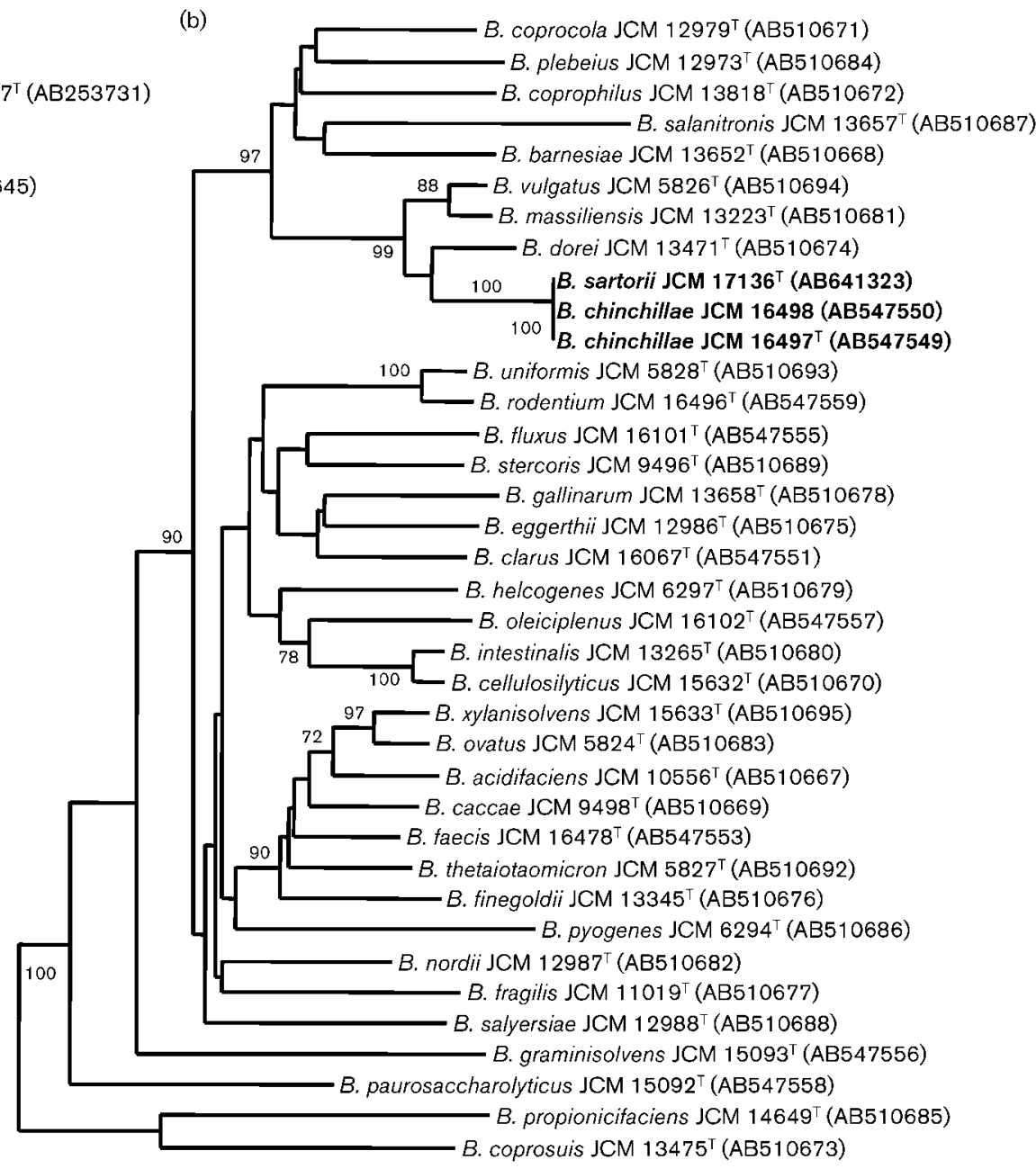

10.02

Fig. 1. Phylogenetic tree based on 16S rRNA (a) and hsp60 (b) gene sequences showing the relationships between Bacteroides sartorii and Bacteroides chinchillae. The tree was reconstructed by the neighbour-joining method. Numbers at nodes indicate the bootstrap values (\%) of 1000 replicates. Bars, 0.01 (a) or 0.02 (b) substitutions per nucleotide position. 
Table 3. DNA $\mathrm{G}+\mathrm{C}$ contents and levels of DNA relatedness

\begin{tabular}{|lcrrr|}
\hline Strain & $\begin{array}{c}\text { DNA G+C } \\
\text { content (mol\%) }\end{array}$ & \multicolumn{3}{c|}{$\begin{array}{c}\text { DNA relatedness } \\
\text { (\%) with: }\end{array}$} \\
\cline { 3 - 5 } & & $\mathbf{1}$ & $\mathbf{2}$ & $\mathbf{3}$ \\
\hline 1. B. sartorii JCM 17136 & & 100 & 79 & 74 \\
2. B. chinchillae JCM 16497 & 45.5 & 79 & 100 & 94 \\
3. B. chinchillae JCM 16498 & 44.1 & 87 & 105 & 100 \\
\hline
\end{tabular}

values are slightly lower than that of B. sartorii JCM $17136^{\mathrm{T}}$ (45.5 mol\%). The levels of DNA-DNA relatedness among B. sartorii JCM $17136^{\mathrm{T}}$, B. chinchillae JCM $16497^{\mathrm{T}}$ and JCM 16498 are shown in Table 3 and demonstrate that these three strains represent a single species. Consequently, $B$. chinchillae (Kitahara et al., 2011) is a later heterotypic synonym of B. sartorii (Clavel et al., 2010).

\section{Emended description of Bacteroides sartorii Clavel et al. 2010}

The description is as given by Clavel et al. (2010) and Kitahara et al. (2011) with the following modifications: the predominant respiratory quinone is MK-10 (94.8 to $95.5 \%$ ); a minor amount of MK-9 (4.5 to $5.2 \%$ ) is present; and the DNA G $+\mathrm{C}$ content is in the range $44.1-45.5 \mathrm{~mol} \%$.

\section{Acknowledgements}

We thank Ms Natsuko Suzuki and Ms Misako Matsuda for their technical assistance. This work was supported by a research grant from IFO (Institute for Fermentation, Osaka, Japan) (2009-2011), and also by a Grant-in-Aid from the Scientific Research from the Japan Society for the Promotion of Science to M. S. (no. 23580126).

\section{References}

Clavel, T., Saalfrank, A., Charrier, C. \& Haller, D. (2010). Isolation of bacteria from mouse caecal samples and description of Bacteroides sartorii sp. nov. Arch Microbiol 192, 427-435.

Ezaki, T., Hashimoto, Y. \& Yabuuchi, E. (1989). Fluorometric deoxyribonucleic acid-deoxyribonucleic acid hybridization in microdilution wells as an alternative to membrane filter hybridization in which radioisotopes are used to determine genetic relatedness among bacterial strains. Int J Syst Bacteriol 39, 224-229.
Felsenstein, J. (1985). Confidence limits of phylogenies: an approach using the bootstrap. Evolution 39, 783-791.

Kimura, M. (1980). A simple method for estimating evolutionary rates of base substitutions through comparative studies of nucleotide sequences. J Mol Evol 16, 111-120.

Kitahara, M., Tsuchida, S., Kawasumi, K., Amao, H., Sakamoto, M., Benno, Y. \& Ohkuma, M. (2011). Bacteroides chinchillae sp. nov. and Bacteroides rodentium sp. nov., isolated from chinchilla (Chinchilla lanigera) faeces. Int J Syst Evol Microbiol 61, 877-881.

Komagata, K. \& Suzuki, K. (1987). Lipid and cell-wall analysis in bacterial systematics. Methods Microbiol 19, 161-207.

Kuykendall, L. D., Roy, M. A., O'Neill, J. J. \& Devine, T. E. (1988). Fatty acids, antibiotic resistance, and deoxyribonucleic acid homology groups of Bradyrhizobium japonicum. Int J Syst Bacteriol 38, 358-361.

Larkin, M. A., Blackshields, G., Brown, N. P., Chenna, R., McGettigan, P. A., McWilliam, H., Valentin, F., Wallace, I. M., Wilm, A. \& other authors (2007). CLUSTAL $W$ and CLUSTAL_X version 2.0. Bioinformatics 23, 2947-2948.

Marmur, J. (1961). A procedure for the isolation of deoxyribonucleic acid from microorganisms. J Mol Biol 3, 208-218.

Miller, L. T. (1982). Single derivatization method for routine analysis of bacterial whole-cell fatty acid methyl esters, including hydroxy acids. J Clin Microbiol 16, 584-586.

Saito, H. \& Miura, K. I. (1963). Preparation of transforming deoxyribonucleic acid by phenol treatment. Biochim Biophys Acta 72, 619-629.

Saitou, N. \& Nei, M. (1987). The neighbor-joining method: a new method for reconstructing phylogenetic trees. Mol Biol Evol 4, 406425.

Sakamoto, M. \& Ohkuma, M. (2010). Usefulness of the $h s p 60$ gene for the identification and classification of Gram-negative anaerobic rods. J Med Microbiol 59, 1293-1302.

Sakamoto, M., Suzuki, M., Umeda, M., Ishikawa, I. \& Benno, Y. (2002). Reclassification of Bacteroides forsythus (Tanner et al. 1986) as Tannerella forsythensis corrig., gen. nov., comb. nov. Int J Syst Evol Microbiol 52, 841-849.

Sakamoto, M., Suzuki, N. \& Benno, Y. (2010). hsp60 and 16S rRNA gene sequence relationships among species of the genus Bacteroides with the finding that Bacteroides suis and Bacteroides tectus are heterotypic synonyms of Bacteroides pyogenes. Int J Syst Evol Microbiol 60, 2984-2990.

Shah, H. N. (1992). The genus Bacteroides and related taxa. In The Prokaryotes, 2nd edn, pp. 3593-3607. Edited by A. Balows, H. G. Trüper, M. Dworkin, W. Harder \& K. H. Schleifer. New York: Springer.

Tamaoka, J. \& Komagata, K. (1984). Determination of DNA base composition by reversed-phase high-performance liquid chromatography. FEMS Microbiol Lett 25, 125-128. 